\title{
Lesions of basal ganglia due to disulfiram neurotoxicity
}

\author{
D Laplane, N Attal, B Sauron, A de Billy, B Dubois
}

\begin{abstract}
Three cases of disulfiram induced Parkinsonism and frontal lobe-like syndrome associated with bilateral lesions of the lentiform nuclei on CT scan are reported. Symptoms developed either after an acute high dose of disulfiram (one case) or after several days to weeks of disulfiram treatment (two cases) and persisted over several years in two patients. These observations suggest that basal ganglia are one of the major targets of disulfiram neurotoxicity. The mechanisms of the lesions of basal ganglia may involve carbon disulfide toxicity.
\end{abstract}

(F Neurol Neurosurg Psychiatry 1992;55:925-929)

Various central neurological manifestations following disulfiram intoxication have been described. ${ }^{1-10}$ They include symptoms suggestive of basal ganglia dysfunction, such as parkinsonism and catatonia. ${ }^{26-10}$ Lidy et al reported hypodensities of basal ganglia on CT scan after acute disulfiram intoxication, ${ }^{9}$ but no clear relation has been established between parkinsonism or catatonia due to disulfiram toxicity and basal ganglia lesions. A recent extensive review of disulfiram induced catatonia failed to mention any possible implication of such lesions in the catatonic syndrome. ${ }^{2} \mathrm{We}$ report three cases in which symptoms indicative of basal ganglia dysfunction were associated with documented lesions of the basal ganglia after disulfiram intoxication.

\section{Case reports}

Case 1

A 42 year old black woman from Guyana with a five year history of alcohol abuse had been treated on two occasions with disulfiram. On the evening of admission she had voluntarily taken 75 disulfiram $500 \mathrm{mg}$ tablets, half a litre of champagne, 5-10 diazepam $10 \mathrm{mg}$ tablets, and 40 B1-B6-B12 vitamin pills. Initially alert, she was admitted to the hospital emergency unit, where she refused gastric lavage. Results of neurological examination were described as normal. Within five days she progressively became somnolent and dysarthric, with limited comprehension for simple commands. She experienced nightmares and auditory hallucinations, along with paranoid delirium. These symptoms subsided over the following days. Results of electroencephalography were normal. Laboratory test results were within normal limits, except for moderate macrocytic anemia.

Three weeks after her admission a generalised tremor of the extremities was observed at rest, and she developed dysphagia and difficulties in swallowing consistent with pseudobulbar palsy. She was dysarthric, with a nasalised and monotonous voice and buccofacial apraxia. Imperious micturition was noted. The plantar reflexes were flexor and the cutaneous abdominal reflexes were not elicited. The facial reflexes were brisk. She kept her eyelids wide open, with rare blinking. Additional neurological findings included signs of polyneuropathy, with sural biopsy showing acute axonopathy. She received carbamazepine ( $200 \mathrm{mg}$ daily) for painful dysaesthesias, as well as vitamins. Results of tests for B12 vitamins, folates, blood ammonia, and urinary porphyrins and serum and urine screens for heavy metals were normal. Spinal fluid examined on day 9 was normal. An EEG showed diffuse symmetrical slowing in the theta and delta range, without focal or epileptiform abnormalities. On about day 32, her condition stabilised and then gradually improved. A few days later myoclonic jerks affecting both arms were noted; these subsidised in the following week.

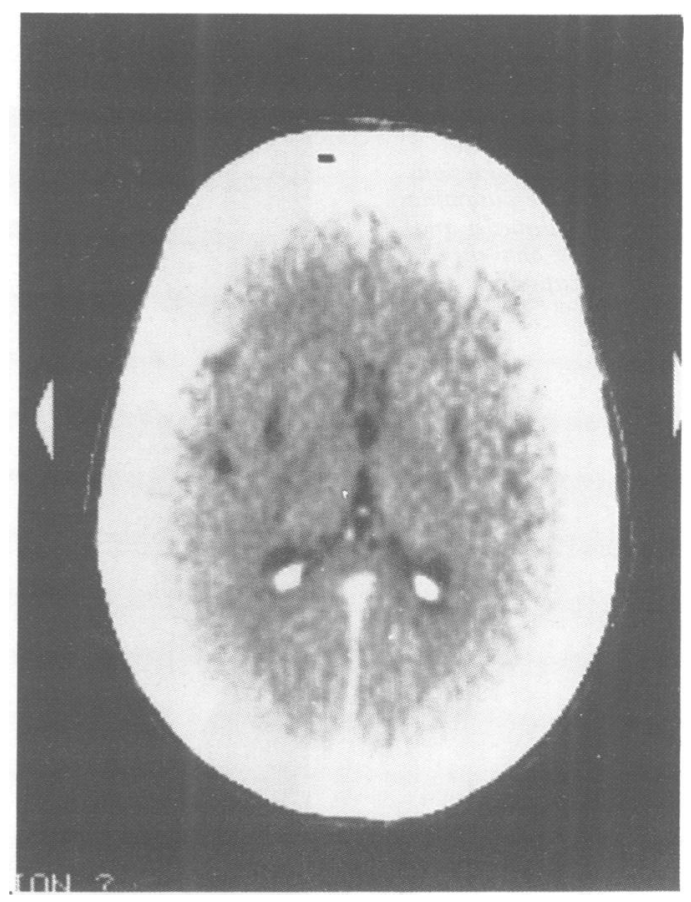

Figure 1 Case 1: horizontal CT scan showing small bilateral lucencies in the putamen. 
CT scans performed one and two months after admission revealed almost symmetrical bilateral low density lesions of the basal ganglia, occupying the putaminal nuclei (fig 1). On discharge two months after admission the patient had totally recovered.

\section{Case 2}

A 23 year old man had been an alcoholic for eight years; he had been started on disulfiram $1 \mathrm{~g}$ daily eight weeks before admission and had abstained from alcohol. His personality was considered to be sociopathic. His history included several admissions to hospital for alcoholic treatment and mild depression.

Seven weeks after disulfiram had been started he was noted to have a progressively worsening staggering gait. $\mathrm{He}$ was thought to have resumed taking alcohol, and disulfiram was increased to $2 \mathrm{~g}$ daily. In 48 hours he was admitted to an intensive care unit unresponsive. Examination did not reveal any focal neurological signs. The plantar reflexes were flexor and the deep tendon reflexes were absent. The patient was put on a ventilator because of cyanosis and bronchial obstruction. A chest radiograph did not show any pulmonary infection. Arterial blood gas levels (room air) revealed a $\mathrm{PaO}_{2}$ of $58 \mathrm{~mm} \mathrm{Hg}$, $\mathrm{PaCO}_{2} 31 \mathrm{~mm} \mathrm{Hg}$, and $\mathrm{pH} \mathrm{7} \cdot 27$. Serum alcohol was negative. Laboratory results showed leucocytosis and diabetic ketoacidosis. Treatment with intravenous insulin was started. A first lumbar puncture was traumatic, with protein $0.3 \mathrm{~g} / 100 \mathrm{ml}$. An EEG showed diffuse slowing, without any paroxysmal activity. Disulfiram was withheld.

On day 3 the patient was alert and extubated. Insulin dosage was reduced. The next morning, ventilation was again required because of increasing impairment of consciousness. Facial myoclonus was noted, and a second EEG showed generalised epileptiform

Figure 2 Case 2. horizonatal CT scan showing bilateral lesions occupying the putaminal and pallidal nuclei and their extent onto the external capsulae. waves. Phenobarbital $20 \mathrm{mg}$ daily and nitrazepam $3 \mathrm{mg}$ daily were started. A CT scan performed on day 5 showed bilateral low density areas occupying the lentiform nuclei and extending onto the internal capsulae. On day 10 a chest radiograph showed left lobar atelectasis and pleural effusion at the base of the lung. Pleural puncture showed bacterial infection with Klebsiella sp, Staphylococcus aureus and Escherichia coli, for which treatment with penicillin, metronidazole, and tobramycin was begun. Tracheotomy was performed.

Within three weeks the patient's vigilance, chest, and physical conditions gradually improved, as did EEG and laboratory findings. Blood glucose concentration had normalised and insulin therapy was withheld. Successive lumbar punctures were normal.

One month after admission the patient became agitated and emotionally labile. Meprobamate ( $800 \mathrm{mg}$ day) was given. The facial reflexes were brisk and the velar reflex was absent. No plantar reflex was elicited. Additional findings disclosed signs consistent with peripheral neuropathy, with sural biopsy showing diffuse axonopathy. Laboratory findings showed normal concentrations of serum B12, folate, and urinary porphyrins. Serologic studies for syphilis, $\mathrm{Hbs}$ antigen, antinuclear bodies and serum complement were normal. CT scans performed one and two months after admission showed no change (fig 2). On his discharge two months after admission, the patient's condition had notably improved, but mild proximal extrapyramidal rigidity was noted.

Seven months later, on follow up, the patient had not resumed alcohol consumption and was not taking disulfiram. Examination showed signs of parkinsonism, with extrapyramidal rigidity of both arms, facial akinesia, a typical abnormal posture, and a slowing of the gait. There was no tremor. The patient was severely dysarthric, with tonic stuttering but no palilalia. Blepharospasm and dystonic posture of the left hand were noted. The facial reflexes were brisk and the plantar reflexes were absent. Grasping and sucking reflexes were not elicited. The tendon reflexes were brisk in the arms and absent in the legs. Additional findings showed residual signs of peripheral neuropathy. The CT scan showed no change and cerebrospinal fluid was normal. No treatment was given for parkinsonism. One year and seven months later neurological findings were comparable except for a central reflex neurogenic bladder, for which he received treatment.

Case 3

A 52 year old man with a history of ethanol abuse had received disulfiram (500 mg daily for several months) 12 years previously, at which time he stopped consuming alcohol. $\mathrm{He}$ was being treated with phenobarbital for epilepsy. His history did not reveal any psychiatric disease.

He was admitted to hospital because of faintness. He was soon noticed to have strange behaviour, which had been observed by his 
Figure 3 Case 3: bilateral low density putaminal and pallidal areas on a horizontal CT slice.

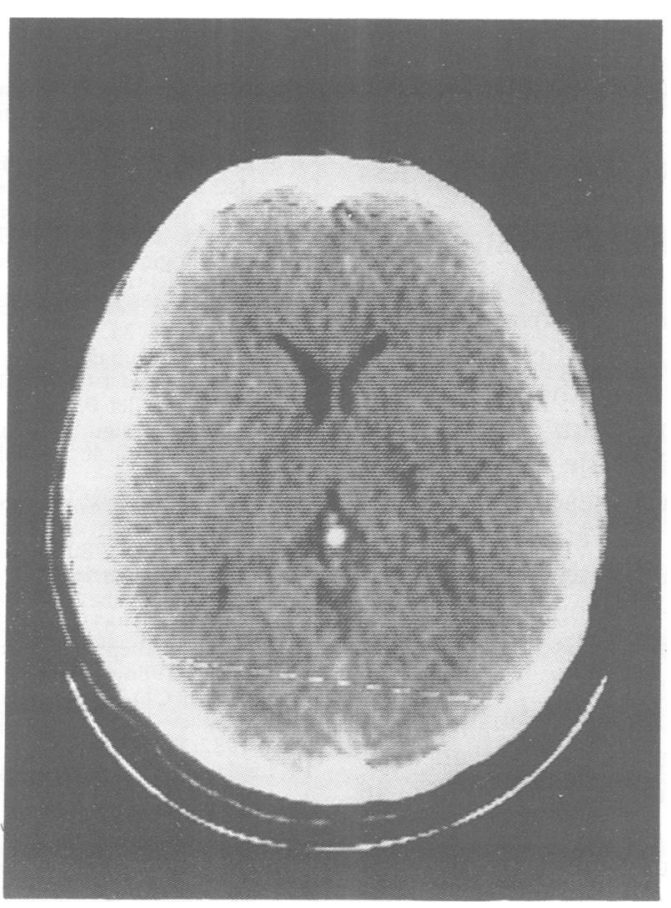

relatives ever since he took disulfiram and had remained stable for 12 years. The most striking features were his lack of initiative, volition, and spontaneous activity, although he could be stimulated into action by his relatives. $\mathrm{He}$ would stay in his room and lie in bed all day, talking to no one, but he would answer questions appropriately and perform complex tasks on request. He was not apparently bored, nor did he express sadness. He did not exhibit compulsive or stereotyped activity. Results of neurological examination were normal. EEG, routine laboratory tests, and cerebrospinal fluid were unremarkable.

Neuropsychological assessment revealed that intellectual function was within normal limits (IQ on the Wechsler adult intelligence scale was 93). Linguistic ability, gestural specific activities, calculation, and drawings were normal. Orientation was preserved in time and space. There was no impairment of learning and acquisition (Wechsler MS MQ was 100) either of old or recent personal memory. Mental control substests were well performed. Verbal fluency was very poor for the enumeration of words beginning with " $\mathrm{m}$ " (one within 60 seconds). The elaboration of new strategies and the sequential programming of activities were disturbed, as shown by the Wisconsin card sorting test (only two categories achieved) and Luria's graphic series. Personality (evaluated by the Minnesota multiphasic personality inventory) was not impaired; depressive rating scales were negative, but he showed blunted affect.

CT scans showed bilateral low density lesions that projected onto the pallidal and putaminal areas (fig 3. An MRI scan was performed five months later and showed a right side lesion involving parts of the putamen.

\section{Discussion}

In the three cases that we report, symptoms suggestive of basal ganglia disease ${ }^{11-13}$ were observed after disulfiram treatment. Two patients developed parkinsonism and pseudobulbar-like syndrome and one developed blepharospasm. The third patient did not show motor disorders but exhibited "loss of drive" or more specifically "loss of psychic self activation." ${ }^{14}$ This behavioural disorder, which resembles the negative symptoms of schizophrenia or the mild forms of catatonia, ${ }^{15}$ has been reported recently to result from basal ganglia lesions. ${ }^{15-18}$

The symptoms exhibited by the patients were clearly related to disulfiram and to no other pathological condition in patients 1 and 3. Patient 1 developed parkinsonian-like symptoms after taking disulfiram together with alcohol. Acute alcohol intoxication or withdrawal may provide parkinsonism in chronic alcoholics with underlying parkinsonian pathology, ${ }^{19}$ but lesions of the lentiform nuclei on CT scan due to alcohol alone have not been described. Although patient 3 was only seen 12 years after disulfiram treatment, it was clear from his relatives that his behavioural disorders started at that time but were not considered severe enough to need medical care. The relation between disulfiram and cerebral insult may be more problematic in patient 2 , who suffered from hypoxia due to pulmonary infection, since the vulnerability of basal ganglia lesions to anoxic injury has long been recognised. ${ }^{15} 20-23$ However, hypoxia in this patient was moderate, as shown by blood gases, and probably insufficient to induce signs of brain hypoxia. ${ }^{20}$ In addition, bilateral ganglionic low density lesions were seen on CT scan only five days after the patient was intubated, and these lesions usually take longer to develop after anoxia. Indeed, in recently reported cases, CT scan performed a few days after cerebral anoxia showed high density ganglia lesions. ${ }^{22} 23$

CT scans showed bilateral lesions of basal ganglia in all patients. The lesions were confined to the lentiform nuclei, particularly affecting the putamen. In patient 3 who underwent $\mathrm{CT}$ scan long after disulfiram treatment the lesions remained stable over several years, which is evidence in favour of an irreversible mechanism. Interestingly, the lesions were similar in all three cases, whatever the dosages and duration of disulfiram, which ranged from $500 \mathrm{mg}$ daily to an acute intoxication with $37.5 \mathrm{~g}$. This is consistent with previous observations, showing that the incidence of disulfiram intoxication does not differ between groups receiving various dosages. ${ }^{24}$ As disulfiram has a very long half life these phenomena may relate to accumulation of the drug because impaired hepatic function in patients with liver damage induced by alcohol.

Disulfiram induced parkinsonism and catatonia are well documented. ${ }^{26-10}$ In contrast, basal ganglia lesions due to disulfiram have not been commonly reported. ${ }^{9}$ Our data suggest that disulfiram intoxication may be related to such lesions, as is the case with post ence- 
phalitic parkinsonism, ${ }^{25}$ carbon monoxide intoxication, or cerebral anoxia, ${ }^{1820-2326-29}$ The negative CT scans in recently reported cases of catatonia or parkinsonism due to disulfiram $^{210}$ may be because these were less severe cases.

The mechanisms underlying disulfiram induced parkinsonism or catatonia are still controversial. One of the main hypotheses is that the lesions result from the toxicity of carbon disulfide, one of the disulfiram metabolites. $^{3031}$ The symptoms induced by carbon disulfide, which include parkinsonism and peripheral neuropathies, resemble those of disulfiram intoxication. ${ }^{30}{ }^{32}$ Patients 1 and 2 developed peripheral neuropathy after receiving disulfiram, and morphological evidence has been provided for carbon disulfide toxicity in disulfiram neuropathy. ${ }^{33}$ Moreover, histopathological lesions of the globus pallidus and substantia nigra have been observed after chronic exposure to carbon disulfide in animals. $^{34}$

Other authors have suggested involvement of brain dopaminergic transmission in disulfiram neurotoxicity, ${ }^{45}$ and in mice the toxic effects of MPTP on nigrostriatal dopamingeric systems was enhanced by pretreatment with disulfiram. ${ }^{36}$ Indeed, disulfiram induces enzymatic blockade, which impairs the ability to eliminate free radicals. ${ }^{37}$ Interestingly, one of the main hypotheses about the causative factors of Parkinson's disease is that the impairment of dopaminergic nigrostriatal systems results from production of free radicals. ${ }^{38}$ In the experiment on mice, however, disulfiram treatment without MPTP did not impair the dopaminergic systems significantly. Nevertheless, it is difficult from the present data totally to exclude a dopaminergic mechanism, since we have no information on the functioning of the substantia nigra in the patients.

A similar case has recently been reported. ${ }^{39}$

In conclusion, our case reports provide evidence that disulfiram induced extrapyramidal and behavioural disorders may be related to lesions of basal ganglia. It would thus be interesting to perform MRI scans in patients with disulfiram induced neurotoxic reactions. Our observations are consistent with the hypothesis that disulfiram neurotoxicity is mediated through carbon disulfide. They emphasise that basal ganglia lesions are a major site of action for disulfiram neurotoxicity. As indicated from previous experiments, ${ }^{40} 41$ and in agreement with initial case reports, ${ }^{17} 18$ these data suggest that a separate disruption of parallel basal gangliathalamocortical circuits may be involved in the behavioural and motor disorders shown by patients with basal ganglia lesions.

We thank Dr M Smith for English revision.

1 Borrett D, Ashby P, Bilbao J, Carlen P. Reversible, lateonset disulfiram-induced neuropathy and encephalopathy. Ann Neurol 1985;17:396-9.

2 Fisher CM. "Catatonia" due to disulfiram toxicity. Arch Neumol 1989;46:798-804.

3 Fournier E, Fournier A, Rochefort H, Efthymiou ML, Mellerio F. Incidents et accidents du traitment par le disulfiram (antabuse). Therapie 1967;:559-600.

4 Hotson JR, Langston JW. Disulfiram-induced encephalopathy. Arch Neurol 1976;33:141-2.

5 Knee ST, Razani J. Acute organic brain syndrome: a complication of disulfiram therapy. Am $\underset{f}{\mathcal{J}}$ Psychiatry

6 Bouillat J. Encêphalopathie (evec syndrome extra-pyramidal) et polynévrite régressives induites par le disulfiram. Lyon Méd 1980;243:541-3.

7 Aupy M, Latinville D, Bretgnier F, Henry P. Accidents neurologiques inhabituels au disulfiram. Bordeaux Med 1981;14:1101-4.

8 Fontan M, Petit H, Delsahousse J, Ascher J, DecouxPoutignat M. Signes extrapyramidaux d'intoxications aigues ou subaigues par le disulfiram ou disulfiramalcool. aigues ou subaigues par le disul

9 Lidy C, Priollet P, Pepin B. Syndrome pyramidal et extrapyramidal aigu apparu au decours d'une intoxication aigüe par le disulfiram. Nouvelle Presse Med 1979;8:3561.

10 Weddington WW, Marks RC, Verguese JP. Disulfiram encephalopathy as a cause of the catatonia syndrome. $A m$ f Psychiatry 1980;137:1217-9.

11 Fross MD, Martin WM, Stoewl AJ, Adam MJ, Ruth TJ Lesions of the putamen: their relevance to dystonia. Neurology 1987;37:1125-9.

12 Jankovic J. Blepharospasm with basal ganglia lesions. Arch Neurol 1986;43:866-8.

13 Marsden CD. The mysterious motor function of the basal ganglia: the Robert Wallenberg Lecture. Neurology 1982;32:514-39.

14 Laplane D. Is "loss of psychic self-activation" an heuristic concept? Behav Neurol 1990;3:27-38

15 Laplane D, Widlocher D, Pillon B, Baulac M, Binoux F. Comportement compulsif d'allure obsessionnelle pa nécrose circonscrite bilatérale pallido-striatale. Encèphalopathie par piqure de guepe. Rev Neurol (Paris) 1981;137:269-76.

16 Laplane D, Baulac M, Pillon B, Papayotopoulo-Achimestos I. Perte de l'auto-activation psychique. Activité compulsive d'allure obbsessionnelle. Lésion lenticulaire bilatèrale. Rev Neurol (Paris) 1982;138:137-41.

17 Laplane D, Levasseur M, Pillon B, Dubois B, Baulac M, Mazoyer B, et al. Obsessive-compulsive and other behavioural changes with bilateral basal ganglia lesions. Brain 1989;112:699-725.

18 Laplane D, Baulac M, Widlocher D, Dubois B. Pure psychic akinesia with bilateral lesions of basal ganglia. $f$ Neurol Neurosurg Psychiatry 1984;41:377-85.

19 Carlen PL, Lee MA, Jacob M, Lishvits O. Parkinsonism provoked by alcoholism. Ann Neurol 1981;9:84-6.

20 Brierley JB, Graham DI. Hypoxia and vascular disorders of the central nervous system. Edwards; Hume Adams J, Corsellis JAN, Duchen LW, eds. Greenfeld's neuropathology; 4th ed. London: Edward Arnold 1984:125-207.

21 Jellinger $\mathrm{K}$. Exogenous lesions of the pallidum. In: Vinken PJ, Bruyn GW, Klawans HL, eds. Handbook of clinical neurology, 49. Amsterdam: Elsevier, 1986, pp465-91.

22 Bamford J, Bodanski H, Bradey N, Currie S, Barnett D. Rapid development of basal ganglia hyperdensities caused by anoxia. $\mathcal{F}$ Neurol Neurosurg Psychiatry 1988;51: $1364-72$.

23 IwasakiY, Kinoshita M, Takamiya K. Rapid development of basal ganglia calcification caused by anoxia. $\mathcal{f}$ Neurol Neurosurg Psychiatry 1988;51:449-50.

24 Branchey L, Davis W, Lee KL, Fuller RK. Psychiatric complications of disulfiram treatment. Am $\mathcal{F}$ Psychiatry 1980;137:1217-9.

25 Martin P. The globus pallidus in post-encephalitic parkinsonism. F Neurol Sci 1965;2:344-65.

26 Lapresle J, Fardeau M. Anatomical study of brain lesions following intoxication with carbon monoxide ( 22 cases). Prog Brain Res 1967;24:31-74.

27 Nardizzi LR. Computerized tomographic correlate of carbon monoxide poisoning. Arch Neurol 1979;24:31-74.

28 Illum F. Calcification of the basal ganglia following carbon monoxide poisoning. Neuroradiology 1980;36:213-4.

$29 \mathrm{Kim}$ KS, Weinberg PE, Suh JH, Ho SU. Acute carbon monoxide poisoning: computed tomography of the brain. monoxide poisoning: computed tomog

30 Kane FJ Jr. Carbon disulfide intoxication from overdosage of disulfarim. Am $\mathcal{f}$ Psychiatry 1970;127:690-4.

31 Rainey JM. Disulfiram toxicity and carbon disulfide poisoning. Am F Psychiatry 1977;134:371-8.

32 Peters HA, Levine RL, Matthews CG, Chapman LJ. Extrapyramidal and other neurologic manifestations associated with carbon disulfide fumigant exposure. Arch Neurol 1988;45:537-40.

33 Ansbacher LE, Bosch P, Cancilla PA. Disulfiram neuropathy: a neurofilamentous distal axonopathy. Neurology 1982;32:424-8.

34 Richter RB. Degeneration of the basal ganglia in monkeys from chronic carbon disulfide poisoning. $\mathcal{f}$ Neuropath Exp Neurol 1945;4:324-53.

35 Musachio J, Goldstein M, Anagnoste B. Inhibition of dopamine-beta hydroxylase by disulfiram in vivo. $\mathcal{F}$ Pharmacol Exp Ther 1967;157:96-102.

36 Corsini GU, Pintus S, Chuang CC, Weiss JF, Kopin IJ. 1-methyl-4-phenyl-1,2,3,6-tetrahydropyridine (MPTP) neurotoxicity in mice is enhanced by pretreatment with neurotoxicity in mice is enhanced by pretreatment with
diethyldithiocarbamate. Eur $\mathcal{f}$ Pharmacol 1985;119: $127-8$.

37 Hekkila RE, Cabbat FS, Cohen G. In vivo inhibition of superoxide dismutase in mice by diethyldithiocarbamate.
$\mathcal{f}$ Biol Chem $1976 ; 251: 2182$. 
38 Langston JW. Current theories on the cause of Parkinson's disease. I Neurol Neurosurg Psychiatry 1989;(supp): 13-17.

39 Krauss JK, Mohadjer M, Wakloo AK, Mundinger F. Dystonia and akinesia due to pallidoputaminal lesions after disulfiram intoxication. Movement Disorders
1991;6:166-77.

40 Alexander GE, DeLong MR, Strick PL. Parallel organization of functionally segregated circuits linking basal ganglia and cortex. Ann Rev Neurosci 1988;9:357-81

41 DeLong MR. Primate models of movement disorders of basal ganglia origin. Trends Neurosci 1990;13:281-5.
Bourneville's tuberous sclerosis: "When the cat is away ...."

Whilst deputising for Mr L J F Delasiauve at the Salpêtrière on 18 July 1867, Désiré Magliore Bourneville (1840-1909) observed a child with the syndrome which now bears his name. He published the case promptly ${ }^{1}$ and thereby his name gained eponymous precedence over Dr Hartdegen who made similar observations at the same time. ${ }^{2}$ Bourneville's patient was L Marie aged three, born of parents without neurological abnormality or consanguinity.

“. . . breast fed by a wet nurse until 14 months. During this time she may have had several convulsions restricted to the eyes. At two years seizures appeared, during which the arms shook and turned slightly. It was particularly in the head. Marie never walked or talked. She gradually deteriorated....a hopeless case.

The eyes are dull ... Rosaceous and pustular acne(sic) of the face; a confluent vesiculopapular rash over the nose, cheeks and forehead; numerous small mollusca on the nape of the neck, which is abnormally short. . . The right arm is paralysed, not complete. . . The left leg is longer and heavier than the right. The right thigh is adducted and flexed on the pelvis; the foot is flat, in varus, and violaceous. . . The legs are bent and crossed in bed. Constant dribbling .. The seizures came in series... April 20th-30th fits. . enema of bromide of camphor 2 grains."

After further fits the child died on 7 May at $3 \mathrm{am}$. At necropsy the brain weighed $1000 \mathrm{gm}$. He saw lesions: "rounded islets, forming protuberances of vari- able size. They are whitish and opaque. . . a sort of hypertrophic sclerosis of various parts of the convolutions. The cavity of the lateral ventricle is normal. Islets. . . in frontal. . temporal convolutions... corpus callosum, hippocampal convolution, Ammon's horn, paracentral lobule, corpus striatum. The right kidney showed three whitish mamillary hard masses projecting 3-5 mm. One is the size of a walnut. In addition 15 other small masses. .. when cut have the appearance of cancerous tissue. The left kidney shows similar but less numerous lesions.

The origin of this illness is obscure."

Bourneville clearly described the mental retardation, adenoma sebaceum, and the malformed sclerotic tubers of the brain. He subtitled the case "Tuberous sclerosis of cerebral convolutions: Idiocy and hemiplegic epilepsy." He described similar tubers in the kidneys, though he thought the latter appeared cancerous. He recorded both focal and clonic convulsive fits. The initial fits "especially the head" may resemble infantile spasms, but there were plainly focal and convulsive elements. And, it is likely that the child had an infantile pattern of right hemiparesis, though flexion and adduction of both arms and legs is described. He does not mention spasticity or reflexes.

JMS PEARCE

1 Bourneville, Contribution a létude de l'idiotie. Archives de Neurologie 1880;1:69-91.

2 Hartdegen A. Ein fall von multipler Vehärtung des Grosshirns nebst histologisch eigenartigen harten Geschwülsten der Seitenventrikel ("Glioma gangliocellulare") be einem Neugeborenen. Arch Psychiat 1880;11:117-31. 